\author{
Marquette University \\ e-Publications@Marquette
}

Biomedical Engineering Faculty Research and

Publications

Biomedical Engineering, Department of

$1-2016$

\title{
Assessing Photoreceptor Structure Associated with Ellipsoid Zone Disruptions Visualized with Optical Coherence Tomography
}

\author{
Drew Scoles \\ University of Rochester \\ John A. Flatter \\ Medical College of Wisconsin \\ Robert F. Cooper \\ Marquette University \\ Christopher S. Langlo \\ Medical College of Wisconsin \\ Scott Robison \\ Medical College of Wisconsin
}

See next page for additional authors

Follow this and additional works at: https://epublications.marquette.edu/bioengin_fac

Part of the Biomedical Engineering and Bioengineering Commons

\section{Recommended Citation}

Scoles, Drew; Flatter, John A.; Cooper, Robert F.; Langlo, Christopher S.; Robison, Scott; Neitz, Maureen; Weinberg, David V.; Pennesi, Mark E.; Han, Dennis P.; Dubra, Alfredo; and Carroll, Joseph, "Assessing Photoreceptor Structure Associated with Ellipsoid Zone Disruptions Visualized with Optical Coherence Tomography" (2016). Biomedical Engineering Faculty Research and Publications. 410.

https://epublications.marquette.edu/bioengin_fac/410 


\section{Authors}

Drew Scoles, John A. Flatter, Robert F. Cooper, Christopher S. Langlo, Scott Robison, Maureen Neitz, David V. Weinberg, Mark E. Pennesi, Dennis P. Han, Alfredo Dubra, and Joseph Carroll 


\title{
Assessing Photoreceptor Structure Associated with Ellipsoid Zone Disruptions Visualized with Optical Coherence Tomography
}

\author{
Drew Scoles \\ Department of Biomedical Engineering, University of Rochester, \\ Rochester, NY \\ John A. Flatter \\ Department of Ophthalmology, Medical College of Wisconsin, \\ Milwaukee, WI \\ Robert F. Cooper \\ Department of Biomedical Engineering, Marquette University, \\ Milwaukee, WI \\ Christopher S. Langlo \\ Department of Cell Biology, Neurobiology, \& Anatomy, \\ Medical College of Wisconsin, \\ Milwaukee, WI \\ Scott Robinson \\ Department of Ophthalmology, Medical College of Wisconsin, \\ Milwaukee, WI
}




\author{
Maureen Neitz \\ Department of Ophthalmology, University of Washington, \\ Seattle, WA \\ David V. Weinberg
}

Department of Ophthalmology, Medical College of Wisconsin, Milwaukee, WI

Mark E. Pennesi

Casey Eye Institute, Oregon Health \& Science University, Portland, OR

Dennis P. Han

Department of Ophthalmology, Medical College of Wisconsin, Milwaukee, WI

\section{Alfredo Dubra}

Department of Ophthalmology, Medical College of Wisconsin, Department of Biomedical Engineering, Marquette University,

Department of Biophysics, Medical College of Wisconsin, Milwaukee, WI Joseph Carroll

Department of Ophthalmology, Medical College of Wisconsin, Department of Biomedical Engineering, Marquette University, Department of Cell Biology, Neurobiology, \& Anatomy, Medical

College of Wisconsin,

Department of Biophysics, Medical College of Wisconsin, Milwaukee, WI 
NOT THE PUBLISHED VERSION; this is the author's final, peer-reviewed manuscript. The published version may be accessed by following the link in the citation at the bottom of the page.

(BCM; $n=1)$ or cone-rod dystrophy (CRD; $n=1$ ) were included. Images were acquired within and around photoreceptor lesions using spectral-domain OCT (SD-OCT), confocal AOSLO and split-detector AOSLO.

Results: There were substantial differences in the extent and appearance of the photoreceptor mosaic as revealed by confocal AOSLO, split-detector AOSLO and SD-OCT en face view of the ellipsoid zone (EZ).

Conclusions: Clinically available SD-OCT, viewed en face or as B-scan, may lead to misinterpretation of photoreceptor anatomy in a variety of diseases and injuries. This was demonstrated using split-detector AOSLO to reveal substantial populations of photoreceptors in areas of no, low, or ambiguous EZ reflectivity with en face OCT and confocal AOSLO. While it is unclear if these photoreceptors are functional, their presence offers hope for therapeutic strategies aimed at preserving or restoring photoreceptor function.

Keywords: Optical coherence tomography, en face optical coherence tomography, Adaptive optics, photoreceptor, retina

\section{Introduction}

Optical coherence tomography (OCT) is rapidly replacing color fundus photography as the most common retinal imaging modality. ${ }^{1}$ En face OCT has emerged as an important tool for the evaluation of layer specific retinal pathology, enabling visualization of lamina cribrosa, ${ }^{2,3}$ microvasculature, ${ }^{4-6}$ RPE detachment, ${ }^{7-9}$ subretinal fluid, ${ }^{7}$, 10, 11 cystoid macular edema, ${ }^{12}$ outer retinal tubulations ${ }^{13,14}$ and other retinal structures. One of the most promising applications of en face OCT is the measurement of ellipsoid zone (EZ) disruption, to provide insight into photoreceptor structure. To date, en face OCT has been utilized to evaluate photoreceptor structure in macular telangiectasia (MacTel) type $2,{ }^{15}$ diabetic retinopathy, ${ }^{12}$ macular hole, ${ }^{12,}{ }^{16}$ macular degeneration ${ }^{12,17-19}$ and ocular trauma. ${ }^{20}$ Quantification of EZ disruption with en face OCT was recently approved as the primary outcome measure for a therapeutic clinical trial in MacTel, ${ }^{21}$ yet little is known about the in vivo cellular anatomy within and at the margins of these disruptions.

One of the challenges in using en face OCT to evaluate photoreceptor structure is the limited lateral resolution and poor transverse spatial sampling of commercially available OCT systems. By correcting the monochromatic aberrations of the eye, adaptive optics (AO) ophthalmoscopy provides the opportunity to visualize individual rod and cone photoreceptors in normal and diseased retinas. ${ }^{22,23}$ The spatial correlation of disruptions as per confocal AOSLO imaging and

Retina, Vol 36, No. 1 (January 2016): pg. 91-103. DOI. This article is (C) Ophthalmic Communications Society, Inc. and permission has been granted for this version to appear in e-Publications@Marquette. Ophthalmic Communications Society, Inc. does not grant permission for this article to be further copied/distributed or hosted elsewhere without the express permission from Ophthalmic Communications Society, Inc. 
en face OCT in closed globe blunt ocular trauma (cg-BOT) revealed photoreceptor cell disruption in the vicinity of EZ disruptions in OCT images. ${ }^{20}$ Despite increased resolution, confocal AOSLO is also limited, as the technique does not visualize photoreceptors with abnormal outer segment morphology or alignment. ${ }^{31}$ Since many retinal diseases are known to cause loss of the photoreceptor outer segment before loss of the remainder of the cell, ${ }^{24-29}$ this limitation could prevent the accurate interpretation of the photoreceptor mosaic in the vicinity of such disruptions.

AOSLO split-detector imaging ${ }^{30,} 31$ has recently demonstrated the non-invasive visualization of the cone photoreceptor inner segment mosaic, regardless of the status of the corresponding outer segment. ${ }^{31}$ Here, we apply split-detector AOSLO in five subjects with wide ranging retinal pathology to evaluate photoreceptor anatomy within and around EZ disruptions identified with OCT, to determine their anatomical correlates. The data demonstrate that there can be significant residual photoreceptor structure within EZ disruptions identified with en face OCT, and that the borders of the disruption can be more clearly demarcated with the split-detector AOSLO technique.

\section{Methods}

\section{Participants}

Research procedures followed the tenets of the Declaration of Helsinki and informed written consent was obtained from all subjects after explanation of the nature and possible consequences of the study. The study protocol was approved by the institutional review board at the Medical College of Wisconsin.

Axial length measurements were obtained on all subjects (Zeiss IOL Master; Carl Zeiss Meditec, Dublin, CA, USA) in order to determine the scale of AOSLO and OCT images. ${ }^{31}$ Prior to all retinal imaging, the eyes to be imaged were dilated and cycloplegia was induced through topical application of phenylephrine hydrochloride $(2.5 \%)$ and tropicamide (1\%).

Retina, Vol 36, No. 1 (January 2016): pg. 91-103. DOI. This article is (C) Ophthalmic Communications Society, Inc. and permission has been granted for this version to appear in e-Publications@Marquette. Ophthalmic Communications Society, Inc. does not grant permission for this article to be further copied/distributed or hosted elsewhere without the express permission from Ophthalmic Communications Society, Inc. 


\section{En face optical coherence tomography}

Spectral domain optical coherence tomography (Bioptigen, Research Triangle Park, NC, USA) line scans and dense cube scans nominally covering $3 \times 3 \mathrm{~mm}$ (400 A-scans/B-scan; $400 \mathrm{~B}$ scans/volume) were performed in the area of planned AOSLO imaging. Using custom designed Java (Oracle, Redwood City, CA) software, we derived en face summed volume projection images from the SD-OCT volumes of all subjects. These images were created to emphasize structures within the EZ (and in one case, also the interdigitation zone, IZ). The macular volume was exported from the machine as an ".avi" and was uncompressed using the Xuggler (Xuggle Inc., San Francisco, CA) library. Each of the 400 B-scans was read from the volume and marked with a flat contour, which was initially a spline fit to three points along the B-scan. The contour for each B-scan was manually modified by the user by both adding points to the contour and adjusting the axial position of each the points. The number of points and the axial position of the points were different for each B-scan, based on the varying morphology of the EZ (See Figure 1.). At each axial position along the B-scan, the pixels within the contour were averaged, resulting in a 1D average array of gray values along each Bscan. The final en face image was created by combining the 1D average array from each B-scan in the volume (See Figure 1.). All OCT images are displayed on logarithmic scale. All final figures were upsampled to 600 ppi for optimal display using bicubic interpolation in Adobe Photoshop (Adobe Photoshop; Adobe Systems Inc., Mountain View, CA). Naming of the outer retinal bands is based on the recent study by Staurenghi et al. ${ }^{32}$ Here, the band referred to as the EZ is the hyperreflective band that lies just posterior to the ELM, and this has been referred to previously as the inner segment/outer segment junction (IS/OS). The band referred to as the IZ is the hyperreflective band that lies just posterior to the EZ, and this has been referred to previously as the cone outer segment tip band (COST).

Retina, Vol 36, No. 1 (January 2016): pg. 91-103. DOI. This article is (C) Ophthalmic Communications Society, Inc. and permission has been granted for this version to appear in e-Publications@ Marquette. Ophthalmic Communications Society, Inc. does not grant permission for this article to be further copied/distributed or hosted elsewhere without the express permission from Ophthalmic Communications Society, Inc. 


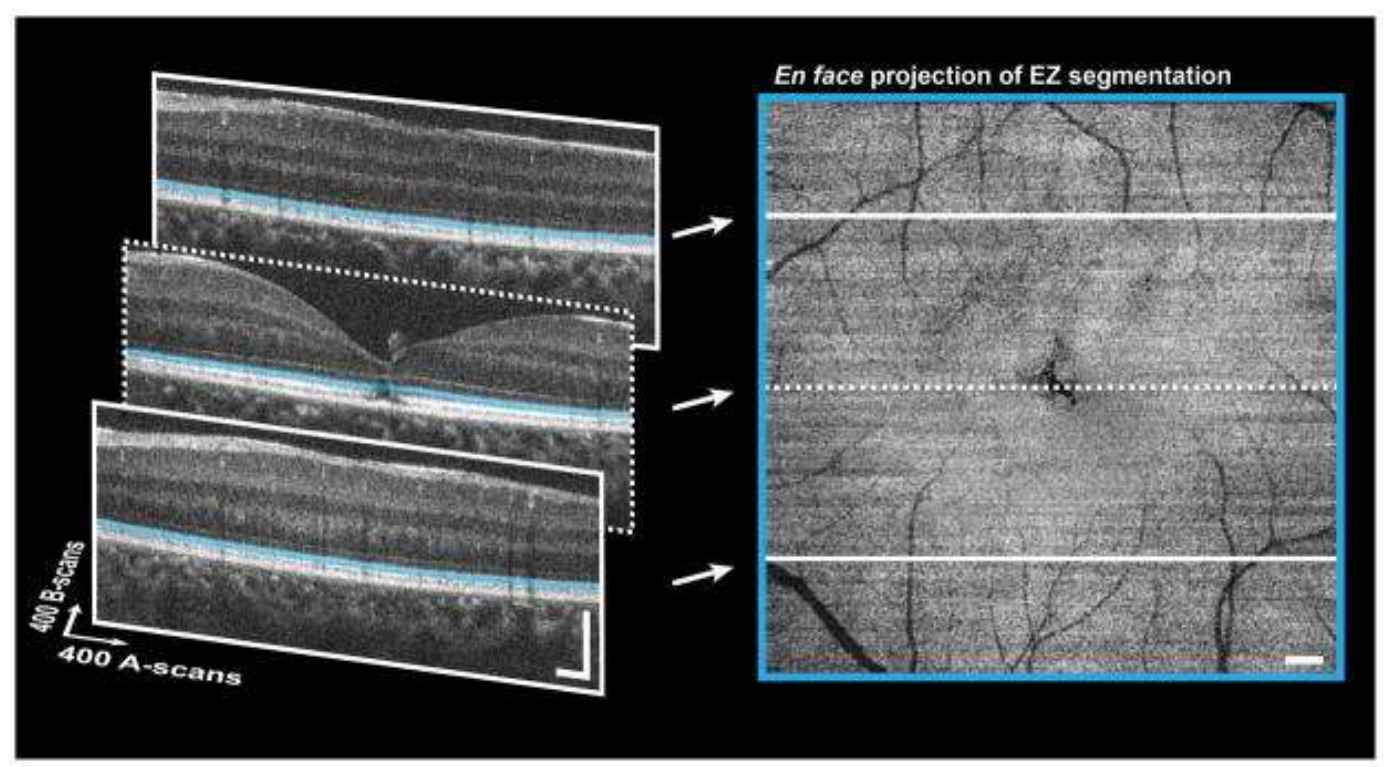

Figure 1. Schematic of the generation of en face summed value projection OCT images

\section{Adaptive optics imaging}

A custom AOSLO ${ }^{33}$ was modified to simultaneously capture confocal and non-confocal light in a split-detection configuration. ${ }^{31}$ Briefly, an annular mirror spatially separated the central $\sim 1$ Airy disc (confocal) portion of the reflected signal to be detected separately, while the non-confocal annulus was divided equally between two additional light detectors. The signals in the two non-confocal detectors were subtracted and then divided by the sum, to form the split-detector image. ${ }^{31}$ Image sequences were acquired at multiple locations, processed and registered using custom software ${ }^{34}$ (Python; Python Software Foundation) as previously described. ${ }^{31}$ Multiple registered images were manually aligned using Adobe Photoshop to ensure AOSLO imaging encompassed the entire EZ disruption, and then were manually aligned to en face OCT using blood vessel shadows or other anatomical landmarks. Confocal and split-detector images are recorded simultaneously at the same wavelength, and thus are in perfect spatial register. While all AOSLO images are displayed here on linear scale, we provide corresponding log display versions (see Figure, Supplemental Digital Content 1). All final figures were upsampled to 600 ppi for optimal display using bicubic interpolation in Adobe Photoshop. 


\section{Results}

Five subjects with clinical diagnoses of closed-globe blunt ocular trauma (cg-BOT; $\mathrm{n}=2$ ), macular telangiectasia type 2 (MacTel; $\mathrm{n}=$ $1)$, blue cone monochromacy (BCM; $n=1$ ) or cone-rod dystrophy $(C R D ; n=1)$ were identified for inclusion in the study. Clinical details are summarized in Table 1 . The EZ disruptions visualized with B-scan and en face OCT varied from mottling (SR_10139 and MP_10097) to focal discontinuities (DH_1192, WW_0923, DW_10105). Confocal AOSLO images from all subjects showed cone and/or rod photoreceptor mosaic disruption. Split-detector AOSLO revealed enlarged photoreceptor inner segments within and on the margins of all EZ disruptions. Of note, the retinal sampling of the en face projections is approximately $7.5 \mu \mathrm{m}$ per pixel, compared to approximately $0.5 \mu \mathrm{m}$ per pixel for AOSLO images.

Table 1. Summary of clinical characteristics

\begin{tabular}{|c|c|c|c|c|c|}
\hline Subject & Eye & BCVA & Age & Diagnosis & Details \\
\hline DH_1192 & OS & $20 / 200$ & 43 & $\begin{array}{l}\text { Cone-rod } \\
\text { dystrophy }\end{array}$ & $\begin{array}{l}\text { Previously reported causative } \\
\text { mutation (p.R838H:c. } 2513 \mathrm{G}>\mathrm{A} \text { ) } \\
\text { identified in } G U C Y 2 D \text { gene. }\end{array}$ \\
\hline DW_10105 & $O D$ & $20 / 25$ & 54 & $\begin{array}{l}\text { Macular } \\
\text { telangiectasis } \\
\text { type } 2\end{array}$ & Stage 2.36 \\
\hline MP_10097 & OD & $20 / 50$ & 43 & $\begin{array}{l}\text { Blue-cone } \\
\text { monochromacy }\end{array}$ & $\begin{array}{l}\text { Previously reported causative } \\
\text { mutation (p.C203R; c.607T >C) } 37 \\
\text { identified in OPN1MW and OPN1LW } \\
\text { genes. }\end{array}$ \\
\hline SR_10139 & OS & $20 / 20$ & 55 & $\begin{array}{l}\text { Closed-globe } \\
\text { blunt ocular } \\
\text { trauma }\end{array}$ & $\begin{array}{l}\text { Motor vehicle accident approximately } \\
35 \text { years prior to imaging. }\end{array}$ \\
\hline WW_0923 & OS & $20 / 20$ & 22 & $\begin{array}{l}\text { Closed-globe } \\
\text { blunt ocular } \\
\text { trauma }\end{array}$ & $\begin{array}{l}\text { Motor vehicle accident approximately } \\
22 \text { months prior to imaging. Patient } \\
\text { previously described at } 7 \text { months post } \\
\text { trauma. }{ }^{20}\end{array}$ \\
\hline
\end{tabular}

Case 1

Subject DH_1192 (43 year-old female) was referred by an outside physician for decreasing visual acuity and color vision abnormalities. Best-corrected visual acuity at the time of research imaging for this study was 20/200 OS, and she had pronounced color

Retina, Vol 36, No. 1 (January 2016): pg. 91-103. DOI. This article is (C) Ophthalmic Communications Society, Inc. and permission has been granted for this version to appear in e-Publications@Marquette. Ophthalmic Communications Society, Inc. does not grant permission for this article to be further copied/distributed or hosted elsewhere without the express permission from Ophthalmic Communications Society, Inc. 
vision impairment on the AOHRR pseudoisochromatic plates ( $D$ value $>0.088$ ). She had a family history of progressive visual impairment beginning with her great-grandmother, including her mother, two out of four siblings and her son. Genetic testing revealed a substitution p. $\mathrm{R} 838 \mathrm{H}$; c. $2513 \mathrm{G}>\mathrm{A}$ in the GUCY2D gene, a mutation reported to cause autosomal dominant cone-rod dystrophy. ${ }^{35}$

Figure 2 summarizes the imaging for this subject's left eye. En face OCT revealed a large elliptical EZ disruption with a central island of decreased reflectivity. The B-scan OCTs through the disruption show that the parafovea has apparently normal retinal lamination, while the elliptical en face disruption has almost no reflectivity, and the central island shows dim and inconsistent reflectivity spread across the EZ and IZ. Co-localized confocal AOSLO imaging revealed that the elliptical island contains very few bright cone photoreceptors and a majority of low-reflectivity structures. The margins of the en face OCT disruption, on the other hand are composed of mostly normal appearing photoreceptors. Split-detector AOSLO revealed that the island within the en face OCT disruption is composed of dramatically enlarged photoreceptor (likely cone) inner segments, surrounded by smaller diameter photoreceptors (likely rods). The darkest area of the en face OCT image contains a sparse population of enlarged photoreceptors.

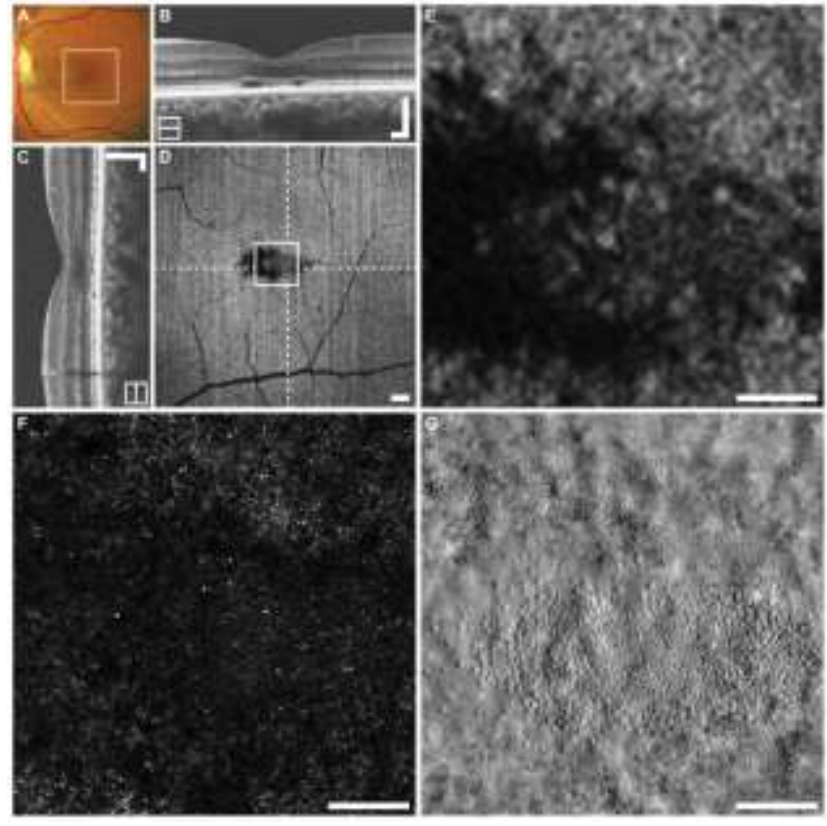

Figure 2. Multimodal imaging in cone-rod dystrophy subject $\mathrm{DH} \_1192$

Retina, Vol 36, No. 1 (January 2016): pg. 91-103. DOI. This article is (C) Ophthalmic Communications Society, Inc. and permission has been granted for this version to appear in e-Publications@Marquette. Ophthalmic Communications Society, Inc. does not grant permission for this article to be further copied/distributed or hosted elsewhere without the express permission from Ophthalmic Communications Society, Inc. 
NOT THE PUBLISHED VERSION; this is the author's final, peer-reviewed manuscript. The published version may be accessed by following the link in the citation at the bottom of the page.

\section{Case 2}

Subject DW_10105 (54 year-old male) presented to the clinic without visual disturbance, but had mildly reduced visual acuity $20 / 30$ OD, 20/50 OS. On exam there was a slight sheen in the temporal foveae, fluorescein angiography showed dilation and leakage of the temporal parafoveal capillaries and subsequent OCT imaging revealed inner and outer retinal cavitations OU. A diagnosis of MacTel was made, and classified as stage $2 \mathrm{OU}$ according to Yannuzzi et al. ${ }^{36}$

Figure 3 summarizes the imaging for this subject's right eye. En face OCT reveals a clover-leaf shaped EZ disruption centered approximately $1^{\circ}$ temporal to the macula. The EZ disruption itself contains two distinct gray levels of reduced reflectivity, the center shows nearly no reflectivity, while the margin is reduced at a level between that of the center and the bright EZ reflectivity in the parafovea. Confocal AOSLO imaging revealed normal (waveguiding) photoreceptors confined to the regions of normal EZ reflectivity. The split-detector AOSLO imaging on the other hand, revealed photoreceptors in the margin of abnormal EZ reflectivity, as well as few photoreceptors well within the EZ disruption itself, which are not visible with any other modality.

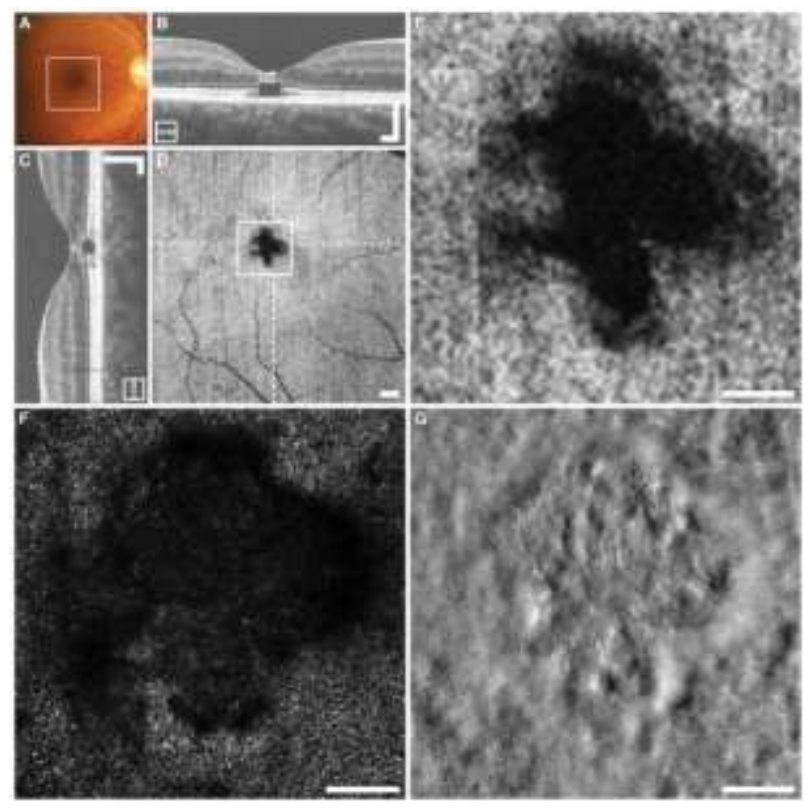

Figure 3. Multimodal imaging in MacTel subject DW_10105

Retina, Vol 36, No. 1 (January 2016): pg. 91-103. DOI. This article is @ Ophthalmic Communications Society, Inc. and permission has been granted for this version to appear in e-Publications@Marquette. Ophthalmic Communications Society, Inc. does not grant permission for this article to be further copied/distributed or hosted elsewhere without the express permission from Ophthalmic Communications Society, Inc. 
NOT THE PUBLISHED VERSION; this is the author's final, peer-reviewed manuscript. The published version may be accessed by following the link in the citation at the bottom of the page.

\section{Case 3}

Subject SR_10139 (55 year-old male) presented with a persistent central scotoma in the right eye from a motorcycle accident approximately 35 years prior. No cause for visual deficit was identified clinically prior to the research visit. Both eyes were imaged, and visual acuity at the time of research imaging was 20/20 OU. A foveal photoreceptor defect was detected in the right eye (not shown), despite no subjective vision loss in the left eye, a parafoveal abnormality was visualized, and is described below.

Figure 4 summarizes the imaging for this subject's left eye. En face OCT in this subject revealed a small EZ disruption in the parafovea, approximately $0.75 \mathrm{~mm}$ supero-temporal from the foveal center. B-scan OCT revealed that the EZ disruption is accompanied by an IZ disruption that spans a larger lateral extent. Confocal AOSLO at this location revealed that the region of EZ and IZ disruption on OCT corresponded to a small square shaped region of reduced photoreceptor waveguiding. The split-detector AOSLO images revealed a mosaic of enlarged photoreceptors in the area of EZ and IZ disruption, surrounded by apparently normal cone and rod photoreceptors. Notably, the disruption size on confocal AOSLO more closely mirrors the size of the IZ disruption as previously reported ${ }^{20}$ (Figure 5); whereas split-detector AOSLO demonstrates there is not complete loss of the photoreceptor mosaic as the EZ disruption might suggest. The dark vertical stripes in the confocal image are likely vessel shadows, which appear as a blur in the split-detector image.

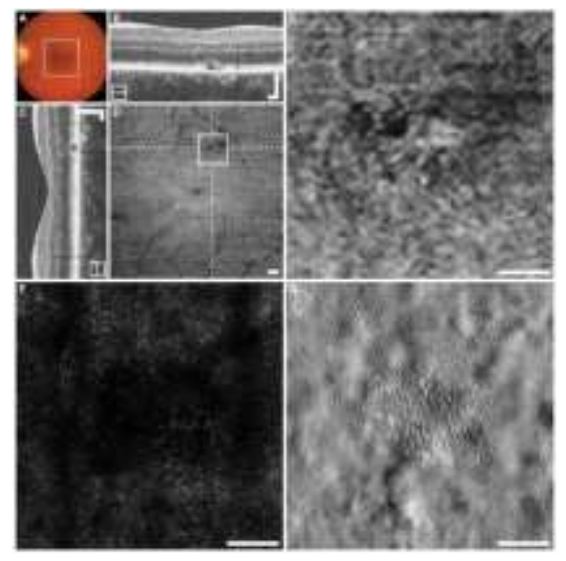

Figure 4. Multimodal imaging in cg-BOT subject SR_10139

Retina, Vol 36, No. 1 (January 2016): pg. 91-103. DOI. This article is @ Ophthalmic Communications Society, Inc. and permission has been granted for this version to appear in e-Publications@Marquette. Ophthalmic Communications Society, Inc. does not grant permission for this article to be further copied/distributed or hosted elsewhere without the express permission from Ophthalmic Communications Society, Inc. 
NOT THE PUBLISHED VERSION; this is the author's final, peer-reviewed manuscript. The published version may be accessed by following the link in the citation at the bottom of the page.

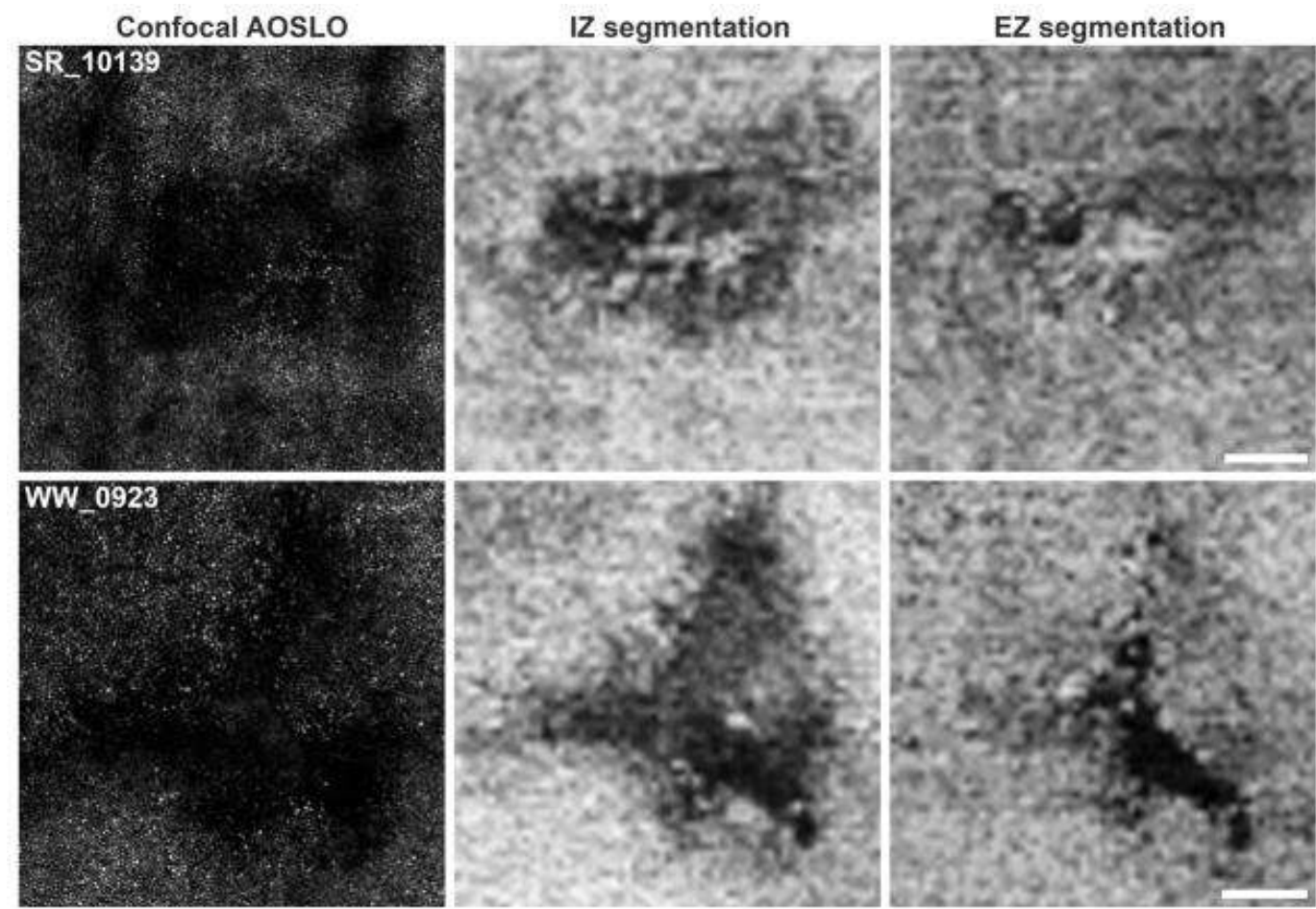

Figure 5. Comparison of disruption size in confocal AOSLO, IZ and EZ en face OCT segmentation

\section{Case 4}

This subject was previously described shortly after trauma. ${ }^{20}$ Briefly, subject WW_0923 (22-year-old male) was an unrestrained driver in a motor vehicle collision in which airbags were deployed. Clinical evaluation on post-trauma day 2 revealed commotio retinae and RPE changes within the macula, as well as wide-spread hemorrhaging in the posterior pole OU. Research imaging presented here was performed 22 months after trauma; he reported a persistent central scotoma OS, yet visual acuity was $20 / 20$ OS at this time.

Figure 6 summarizes the imaging for this subject's left eye. En face imaging revealed a tri-petaloid EZ disruption centered at the fovea. Confocal AOSLO imaging revealed an anchor shaped area of abnormal non-waveguiding photoreceptors that corresponded roughly to the region of EZ disruption. Split-detector imaging revealed a pattern nearly identical to that seen in the en face OCT with a contiguous mosaic of photoreceptors except for the infero-temporal prong. The photoreceptors themselves within areas close to the EZ

Retina, Vol 36, No. 1 (January 2016): pg. 91-103. DOI. This article is (C) Ophthalmic Communications Society, Inc. and permission has been granted for this version to appear in e-Publications@Marquette. Ophthalmic Communications Society, Inc. does not grant permission for this article to be further copied/distributed or hosted elsewhere without the express permission from Ophthalmic Communications Society, Inc. 
disruption vary widely in size over very small regions from dramatically enlarged to nearly normal diameters. As with subject SR_10139, the IZ disruption (as opposed to the EZ disruption) on en face OCT better correlates to confocal AOSLO findings of reduced photoreceptor waveguiding (Figure 5.).

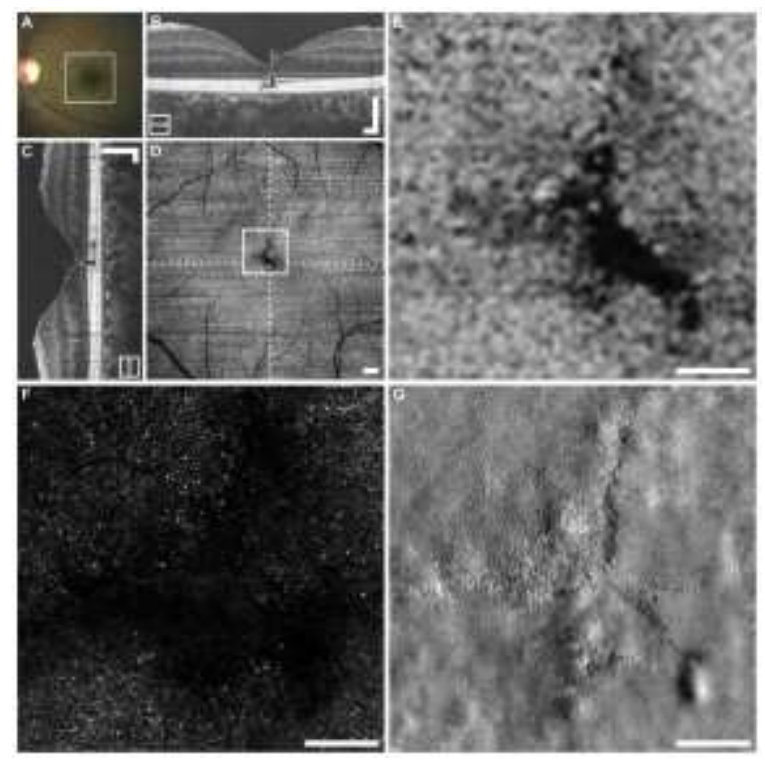

Figure 6. Multimodal imaging in cg-BOT subject WW_0923

\section{Case 5}

Subject MP_10097 (40-year-old male) was previously diagnosed with BCM. Genetic testing revealed a previously reported causative mutation (p.C203R; c.607T>C) ${ }^{37}$ in OPN1MW and OPN1LW genes. He complained of photophobia, problems with dark adaptation, and difficultly with color discrimination. His visual acuity measured $20 / 60+2$ and $20 / 70-1$ in the right and left eye, respectively with a refraction of -4.5 OD and $-5.5 \mathrm{D}$ OS. The anterior segment exam was unremarkable, while fundus exam revealed healthy appearing optic nerves and normal vasculature. There was a blunted foveal light reflex in the right eye. The peripheral retinal exam was unremarkable with exception of a nevus nasal to the optic nerve OD. Octopus kinetic visual fields revealed intact responses to all isopters OU. Multifocal ERGs were nearly unrecordable OU. Full-field ERGs demonstrated normal Dark-adapted 0.01 responses, normal amplitude of the Darkadapted 3.0 response but loss of the oscillatory potentials. Dark- 
adapted cone responses were recorded by subtracting the response to a red flash (KW26 filter) from the matched response to a blue flash (KW47, 47A, 47B, 0.6 ND filters). These were severely attenuated. Light-adapted 3.0 single flash and flicker responses were severely attenuated and prolonged. ERG recordings met or exceeded the ISCEV standards. ${ }^{38}$

Figure 7 summarizes the imaging for this subject's right eye. En face OCT revealed an elliptical area of EZ hyper-reflectivity spanning from the bottom left to the top right corner of the area shown in Figure 7E. Interestingly, the EZ abnormality in this patient is most clearly visualized with B-scan OCT, as the en face OCT shows only a subtle hyper-reflectivity. In contrast to the subjects discussed above (Figures $2,33,44,6), 6)$, en face OCT disruption is demarcated hyper not hypo-reflectivity. Within the disruption the confocal AOSLO image contains severely disrupted photoreceptor mosaic where the vast majority of photoreceptors are non-waveguiding. Despite a near total loss of cone function on ERG, the split-detector image revealed a contiguous photoreceptor mosaic composed of cones at the center, and then rods and cones in the immediate surrounding periphery throughout the areas of little to no reflectivity in the confocal image. The area of greatest EZ reflectivity corresponds spatially to the area of dense cone packing. Although the EZ reflectivity appears normal in the parafovea, the confocal image revealed that the majority of cones are abnormal and non-waveguiding in this region.

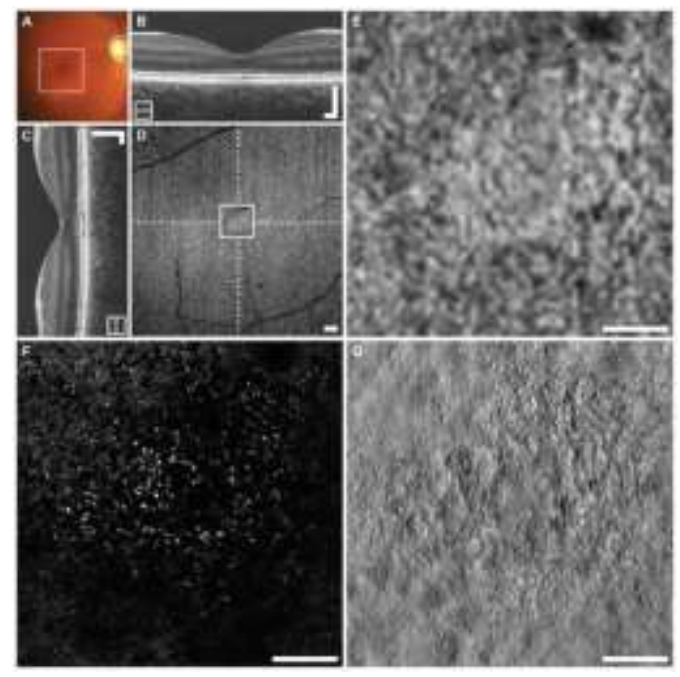

Figure 7. Multimodal imaging in BCM subject MP_10097

Retina, Vol 36, No. 1 (January 2016): pg. 91-103. DOI. This article is (C) Ophthalmic Communications Society, Inc. and permission has been granted for this version to appear in e-Publications@Marquette. Ophthalmic Communications Society, Inc. does not grant permission for this article to be further copied/distributed or hosted elsewhere without the express permission from Ophthalmic Communications Society, Inc. 
NOT THE PUBLISHED VERSION; this is the author's final, peer-reviewed manuscript. The published version may be accessed by following the link in the citation at the bottom of the page.

\section{Discussion}

In this study, we utilized two AOSLO modalities in order to evaluate the photoreceptor structure within EZ disruptions identified with OCT. We do not characterize the visual sensitivity within each disruption, or claim that every photoreceptor visualized with splitdetector is a functional photoreceptor. It has been shown that the EZ integrity can be a good surrogate marker for visual function, ${ }^{16,39-42}$ however, disruption of the EZ band does not always correlate with reduced acuity. ${ }^{43}$ The results here indicate that the integrity of the EZ band is also not a good predictor for presence of photoreceptors. A study of patients recovering from macular hole repair found that the integrity of the external limiting membrane (ELM) rather than EZ in Bscan OCT was a better functional indicator. ${ }^{44}$ All five cases demonstrated here have fully intact ELM over their photoreceptor lesions, which may argue that integrity of the ELM also better predicts photoreceptor anatomy.

Although the physiologic mechanisms for the disruption of photoreceptors are undoubtedly different between these varied conditions, the appearance with AOSLO is nonetheless quite similar. The confocal images fail to identify a large proportion of photoreceptor cells visualized with split-detector AOSLO. Potentially the most unexpected similarity is found between the images in cg-BOT, CRD and MacTel. In these disparate pathologies the en face image shows bright normal appearing EZ surrounding a disruption with two distinct gray-levels. In both of these cases the area of dim EZ signal corresponds to areas of residual photoreceptor structure with enlarged inner segments in the split-detector images, while the area with no reflectivity in OCT shows scant enlarged photoreceptors.

The significance of the split-detector imaging results demonstrated here varies depending on the pathology. As genetic causes of photoreceptor disruption, CRD and BCM are both potentially amenable to future gene therapy approaches to halt the disease and hopefully rescue diseased photoreceptors. ${ }^{45}$ The examples shown here in Figures 2\&7, offer great promise for this approach, since they demonstrate robust populations of photoreceptors at the center of the fovea that could not be visualized with confidence in either confocal 
AOSLO or OCT. There is no gene therapy currently in development for MacTel or cg-BOT, but the finding of photoreceptors with split-detector within areas of $E Z$ disruption is promising nonetheless. The fact that AOSLO imaging is able to follow the anatomic changes of injured photoreceptors as they enlarge and lose their outer segment ${ }^{28,29}$ offers a useful biomarker with which to evaluate a potential therapeutic intervention.

A potential limitation of this study is the lack of hardware eye tracking in the SD-OCT machine used to record the macular volumes. Eye-motion artifacts are visible in some of the en face images shown here, especially towards the ends of the scans. To avoid including corrupted scans, each volume was manually screened for excessive motion between frames before the en face image was generated. Since all en face segmentation was manual, there is also the potential for inaccuracy of the axial position of the segmentation band. This source of error may be significant, but to our knowledge there is currently no automatic segmentation software that can accurately account for the types of discontinuities shown here. The new imaging modality described here, split-detector AOSLO, has slightly lower resolution than confocal and is often unable to resolve rod and foveal cone photoreceptors. ${ }^{31}$ This resolution may limit the quantification of absolute photoreceptor structure in some subjects. As shown above, however, photoreceptors are often enlarged in the vicinity of EZ disruptions, which partially mitigate this limitation. Another limitation comes from the fact that all of the SD-OCT data was acquired through the center of the pupil. Directional OCT techniques ${ }^{48}$ may provide improved visualization of abnormally waveguiding photoreceptors within EZ lesions, and provide more accurate visualization of the lesion boundaries. ${ }^{49}$ Finally, use of AO-OCT techniques may allow imaging the EZ layer at a resolution comparable to that of confocal AOSLO. ${ }^{50-53}$ While it is not known how the absence or disruption of outer segment structure affects the visualization of photoreceptors on AO-OCT images, applying these tools to patients with retinal degenerations may help address this important question.

In summary, here we demonstrate the cellular anatomy within and on the margins of EZ disruptions demonstrated with en face OCT. The results indicate that the interpretation of EZ disruptions visualized by OCT is not as simple as once thought. The absence or presence of

Retina, Vol 36, No. 1 (January 2016): pg. 91-103. DOI. This article is (C) Ophthalmic Communications Society, Inc. and permission has been granted for this version to appear in e-Publications@Marquette. Ophthalmic Communications Society, Inc. does not grant permission for this article to be further copied/distributed or hosted elsewhere without the express permission from Ophthalmic Communications Society, Inc. 
reflectivity in the EZ band does not reliably predict the degree of residual photoreceptor structure. Future studies correlating other imaging modalities, such as AO-OCT and directional OCT, ${ }^{48}$ with clinical OCT are necessary to improve the interpretation of OCT EZ disruptions.

\section{Summary Statement}

Ellipsoid zone disruptions obtained visualized with optical coherence tomography were not predictive of the photoreceptor structure identified with confocal and split-detector adaptive optics scanning light ophthalmoscopy in a number of retinal conditions. These findings challenge the current interpretation of hypo-reflective regions in en face and B-scan optical coherence tomography.

\section{Acknowledgments}

Funding: This publication was supported by NIH grants R01EY017607 (JC), P30EY001931 (JC), P30EY001730 (MN), UL1TR000055, K08EY021186-01 (MEP) and T32GM007356 (DS). Its contents are solely the responsibility of the authors and do not necessarily represent the official views of the NIH. Alfredo Dubra is the recipient of a Career Award at the Scientific Interface from the Burroughs Wellcome Fund. Alfredo Dubra and Mark Pennesi are recipients of career development awards from Research to Prevent Blindness (RPB). This research was also supported by grants from the Foundation Fighting Blindness (JC, AD), RD \& Linda Peters Foundation (JC, AD), Glaucoma Research Foundation Catalyst for a Cure Initiative (AD), the Ray $\mathrm{H}$. Hill Foundation (MN), and unrestricted departmental grants from RPB (OHSU, UW, MCW). This investigation was conducted in a facility constructed with support from the Research Facilities Improvement Program; grant number C06-RR016511 from the National Center for Research Resources, NIH. The funding organizations had no role in the design or conduct of this research.

The authors acknowledge the assistance of Clinton C. Warren, Yusufu N. Sulai and Zachary G. Harvey in the collection of data and preparation of this manuscript.

\section{References}

${ }^{1}$ Swanson E, Huang D. Ophthalmic OCT reaches $\$ 1$ billion per year. Retinal Physician. 2011;8:45.

2 Takayama K, et al. Three-Dimensional Imaging of Lamina Cribrosa Defects in Glaucoma Using Swept-Source Optical Coherence Tomography. Investigative ophthalmology \& visual science. 2013;54:4798-4807.

Retina, Vol 36, No. 1 (January 2016): pg. 91-103. DOI. This article is (C) Ophthalmic Communications Society, Inc. and permission has been granted for this version to appear in e-Publications@Marquette. Ophthalmic Communications Society, Inc. does not grant permission for this article to be further copied/distributed or hosted elsewhere without the express permission from Ophthalmic Communications Society, Inc. 
NOT THE PUBLISHED VERSION; this is the author's final, peer-reviewed manuscript. The published version may be accessed by following the link in the citation at the bottom of the page.

${ }^{3}$ Lee EJ, et al. Three-dimensional evaluation of the lamina cribrosa using spectral-domain optical coherence tomography in glaucoma. Investigative ophthalmology \& visual science. 2012;53:198-204.

${ }^{4} \mathrm{Jia} Y$, et al. Quantitative optical coherence tomography angiography of choroidal neovascularization in age-related macular degeneration. Ophthalmology. 2014;121:1435-1444.

${ }^{5} \mathrm{Kim}$ DY, et al. Noninvasive imaging of the foveal avascular zone with highspeed, phase-variance optical coherence tomography. Investigative ophthalmology \& visual science. 2012;53:85-92.

6 Jia $Y$, et al. Split-spectrum amplitude-decorrelation angiography with optical coherence tomography. Optics express. 2012;20:4710-4725.

7 Rosen RB, et al. Multidimensional en-face OCT imaging of the retina. Optics express. 2009;17:4112-4133.

${ }^{8}$ Coscas $F$, et al. En face enhanced depth imaging optical coherence tomography of fibrovascular pigment epithelium detachment. Investigative ophthalmology \& visual science. 2012;53:4147-4151.

${ }^{9}$ Lumbroso B, et al. Morphologic differences, according to etiology, in pigment epithelial detachments by means of en face optical coherence tomography. Retina. 2011;31:553-558.

10 Lehmann M, et al. Retinal and choroidal changes observed with 'En face' enhanced-depth imaging OCT in central serous chorioretinopathy. The British journal of ophthalmology. 2013;97:1181-1186.

${ }^{11}$ Ferrara D, et al. En face enhanced-depth swept-source optical coherence tomography features of chronic central serous chorioretinopathy. Ophthalmology. 2014;121:719-726.

12 Wanek J, et al. Feasibility of a method for en face imaging of photoreceptor cell integrity. American journal of ophthalmology. 2011;152:807-814.

${ }^{13}$ Wolff $B$, et al. En Face OCT Imaging for the Diagnosis of Outer Retinal Tubulations in Age-Related Macular Degeneration. J Ophthalmol. 2012:542417.

${ }^{14}$ Zweifel SA, et al. Outer retinal tubulation: a novel optical coherence tomography finding. Archives of ophthalmology. 2009;127:15961602.

15 Sallo FB, et al. "En face" OCT imaging of the IS/OS junction line in type 2 idiopathic macular telangiectasia. Investigative ophthalmology \& visual science. 2012;53:6145-6152.

16 Oh J, et al. Photoreceptor inner/outer segment defect imaging by spectral domain OCT and visual prognosis after macular hole surgery. Investigative ophthalmology \& visual science. 2010;51:1651-1658.

17 Gorczynska I, et al. Projection OCT fundus imaging for visualising outer retinal pathology in non-exudative age-related macular degeneration. The British journal of ophthalmology. 2009;93:603-609.

Retina, Vol 36, No. 1 (January 2016): pg. 91-103. DOI. This article is (C) Ophthalmic Communications Society, Inc. and permission has been granted for this version to appear in e-Publications@ Marquette. Ophthalmic Communications Society, Inc. does not grant permission for this article to be further copied/distributed or hosted elsewhere without the express permission from Ophthalmic Communications Society, Inc. 
NOT THE PUBLISHED VERSION; this is the author's final, peer-reviewed manuscript. The published version may be accessed by following the link in the citation at the bottom of the page.

${ }^{18}$. Wojtkowski $M$, et al. Comparison of reflectivity maps and outer retinal topography in retinal disease by 3-D Fourier domain optical coherence tomography. Optics express. 2009;17:4189-4207.

19 Nunes RP, et al. Predicting the progression of geographic atrophy in agerelated macular degeneration with SD-OCT en face imaging of the outer retina. Ophthalmic surgery, lasers \& imaging retina. 2013;44:344-359.

20 Flatter JA, et al. Outer Retinal Structure after Closed-Globe Blunt Ocular Trauma. Retina. 2014

${ }^{21}$ A Phase 2 Multicenter Randomized Clinical Trial of Ciliary Neurotrophic Factor (CNTF) for Macular Telangiectasia Type 2 (MacTel). 2014.

22 Liang J, Williams DR, Miller DT. Supernormal vision and high-resolution retinal imaging through adaptive optics. Journal of the Optical Society of America A: Optics, Image Science, and Vision. 1997;14:2884-2892.

23 Dubra A, et al. Noninvasive imaging of the human rod photoreceptor mosaic using a confocal adaptive optics scanning ophthalmoscope. Biomedical optics express. 2011;2:1864-1876.

${ }^{24} \mathrm{Kolb} \mathrm{H}$, Gouras P. Electron microscopic observations of human retinitis pigmentosa, dominantly inherited. Investigative Ophthalmology and Visual Science. 1974;13:487-498.

25 Szamier RB, Berson EL. Retinal ultrastructure in advanced retinitis pigmentosa. Investigative ophthalmology \& visual science. 1977; 16:947-962.

${ }^{26}$ Gao J, et al. Progressive photoreceptor degeneration, outer segment dysplasia, and rhodopsin mislocalization in mice with targeted disruption of the retinitis pigmentosa-1 (Rp1) gene. Proc Natl Acad Sci U S A. 2002; 99:5698-5703.

27 Johnson PT, et al. Drusen-associated degeneration in the retina. Investigative ophthalmology \& visual science. 2003;44:4481-4488.

${ }^{28}$ Curcio CA, Medeiros NE, Millican CL. Photoreceptor loss in age-related macular degeneration. Investigative ophthalmology \& visual science. $1996 ; 37: 1236-1249$.

${ }^{29}$ Syed N, et al. Evaluation of retinal photoreceptors and pigment epithelium in a female carrier of choroideremia. Ophthalmology. 2001;108:711720.

30 Sulai YN, et al. Visualization of retinal vascular structure and perfusion with a nonconfocal adaptive optics scanning light ophthalmoscope. Journal of the Optical Society of America A: Optics, Image Science, and Vision. 2014;31:569-579.

${ }^{31}$ Scoles $D$, et al. In vivo imaging of human cone photoreceptor inner segments. Investigative ophthalmology \& visual science. $2014 ; 55: 4244-4251$.

Retina, Vol 36, No. 1 (January 2016): pg. 91-103. DOI. This article is (C) Ophthalmic Communications Society, Inc. and permission has been granted for this version to appear in e-Publications@Marquette. Ophthalmic Communications Society, Inc. does not grant permission for this article to be further copied/distributed or hosted elsewhere without the express permission from Ophthalmic Communications Society, Inc. 
NOT THE PUBLISHED VERSION; this is the author's final, peer-reviewed manuscript. The published version may be accessed by following the link in the citation at the bottom of the page.

32 Staurenghi G, et al. Proposed Lexicon for Anatomic Landmarks in Normal Posterior Segment Spectral-Domain Optical Coherence Tomography: The IN*OCT Consensus. Ophthalmology. 2014

33 Dubra A, Sulai Y. Reflective afocal broadband adaptive optics scanning ophthalmoscope. Biomedical optics express. 2011;2:1757-1768.

34 Dubra A, Harvey Z. Registration of 2D Images from Fast Scanning Ophthalmic Instruments. The 4th International Workshop on Biomedical Image Registration; Lübeck, Germany: Springer-Verlag; 2010. pp. 60-71.

35 Kitiratschky VB, et al. Mutation analysis identifies GUCY2D as the major gene responsible for autosomal dominant progressive cone degeneration. Investigative ophthalmology \& visual science. 2008;49:5015-5023.

36 Yannuzzi LA, et al. Idiopathic macular telangiectasia. Archives of ophthalmology. 2006;124:450-460.

37 Carroll J, et al. The effect of cone opsin mutations on retinal structure and the integrity of the photoreceptor mosaic. Investigative ophthalmology \& visual science. 2012;53:8006-8015.

38 Marmor MF, et al. ISCEV Standard for full-field clinical electroretinography (2008 update) Doc Ophthalmol. 2009;118:69-77.

${ }^{39}$ Rangaswamy NV, et al. A comparison of visual field sensitivity to photoreceptor thickness in retinitis pigmentosa. Investigative ophthalmology \& visual science. 2010;51:4213-4219.

40 Park SJ, et al. Morphologic photoreceptor abnormality in occult macular dystrophy on spectral-domain optical coherence tomography. Investigative ophthalmology \& visual science. 2010;51:3673-3679.

${ }^{41}$ Spaide RF, Koizumi H, Freund KB. Photoreceptor outer segment abnormalities as a cause of blind spot enlargement in acute zonal occult outer retinopathy-complex diseases. American journal of ophthalmology. 2008;146:111-120.

42 Sano M, et al. Restored photoreceptor outer segment and visual recovery after macular hole closure. American journal of ophthalmology. 2009;147:313-318.

${ }^{43}$ Chang LK, Koizumi H, Spaide RF. Disruption of the photoreceptor inner segment-outer segment junction in eyes with macular holes. Retina. 2008;28:969-975.

44 Wakabayashi T, et al. Foveal microstructure and visual acuity in surgically closed macular holes: spectral-domain optical coherence tomographic analysis. Ophthalmology. 2010;117:1815-1824.

${ }^{45}$ Cideciyan AV, et al. Human cone visual pigment deletions spare sufficient photoreceptors to warrant gene therapy. Human gene therapy. $2013 ; 24: 993-1006$.

Retina, Vol 36, No. 1 (January 2016): pg. 91-103. DOI. This article is (C) Ophthalmic Communications Society, Inc. and permission has been granted for this version to appear in e-Publications@Marquette. Ophthalmic Communications Society, Inc. does not grant permission for this article to be further copied/distributed or hosted elsewhere without the express permission from Ophthalmic Communications Society, Inc. 
NOT THE PUBLISHED VERSION; this is the author's final, peer-reviewed manuscript. The published version may be accessed by following the link in the citation at the bottom of the page.

${ }^{46}$ Charbel Issa P, et al. Macular telangiectasia type 2. Prog Retin Eye Res. 2012:11.

47 Yannuzzi LA, et al. Idiopathic macular telangiectasia 2006. Retina. 2012;32(Suppl 1):450-460.

48 Lujan BJ, et al. Revealing Henle's fiber layer using spectral domain optical coherence tomography. Investigative ophthalmology \& visual science. $2011 ; 52: 1486-1492$.

49 Panorgias A, et al. Multimodal assessment of microscopic morphology and retinal function in patients with geographic atrophy. Investigative ophthalmology \& visual science. 2013;54:4372-4384.

50 Kocaoglu OP, et al. Adaptive optics optical coherence tomography with dynamic retinal tracking. Biomedical optics express. 2014;5:22622284.

${ }^{51}$ Felberer F, et al. Adaptive optics SLO/OCT for 3D imaging of human photoreceptors in vivo. Biomedical optics express. 2014;5:439-456.

52 Torti C, et al. Adaptive optics optical coherence tomography at 120,000 depth scans/s for non-invasive cellular phenotyping of the living human retina. Optics express. 2009;17:19382-19400.

53 Lee S-H, Werner JS, Zawadzki RJ. Improved visualization of outer retinal morphology with aberration cancelling reflective optical design for adaptive optics - optical coherence tomography. Biomed Opt Express. 2013;4:2508-2517.

Correspondence: Joseph Carroll, The Eye Institute, Medical College of Wisconsin, 925 N 87 ${ }^{\text {th }}$ Street, Milwaukee, WI 53226; Email: jcarroll@mcw.edu

Retina, Vol 36, No. 1 (January 2016): pg. 91-103. DOI. This article is (C) Ophthalmic Communications Society, Inc. and permission has been granted for this version to appear in e-Publications@ Marquette. Ophthalmic Communications Society, Inc. does not grant permission for this article to be further copied/distributed or hosted elsewhere without the express permission from Ophthalmic Communications Society, Inc. 
NOT THE PUBLISHED VERSION; this is the author's final, peer-reviewed manuscript. The published version may be accessed by following the link in the citation at the bottom of the page.

\section{Supplementary Material}

\section{Supplemental Figure}

Supplemental Digital Content 1. AOSLO montages from the 5 subjects reported in the current study:

The left column shows the confocal AOSLO montage presented on a linear display, while the center column shows the same confocal AOSLO montage on a log display. This increases the apparent brightness of some of structures within the dimly reflecting regions, not all of which are photoreceptor in origin. The right column provides the split-detector AOSLO montage on a linear display. Scalebars $=100 \mu \mathrm{m}$.
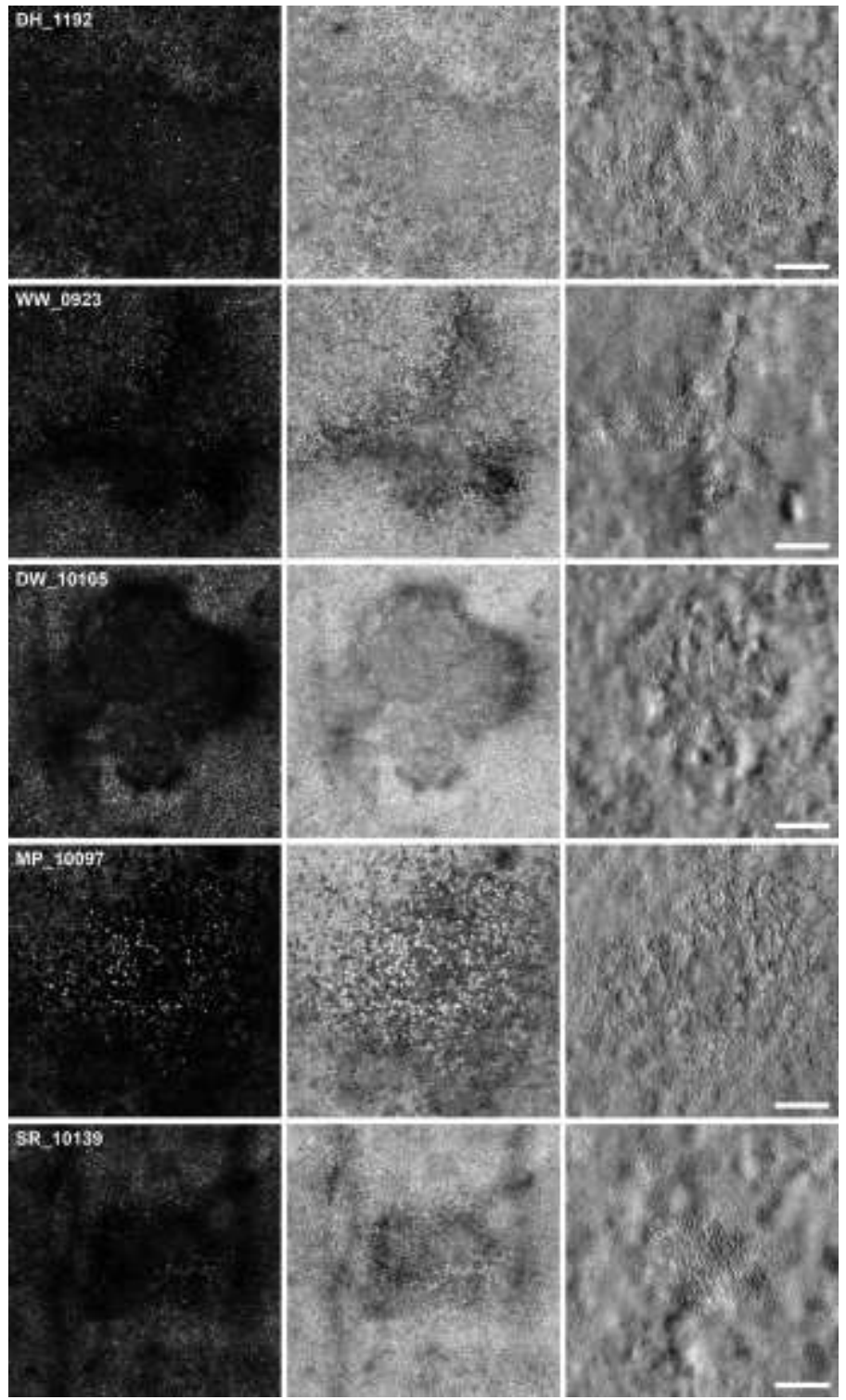

Retina, Vol 36, No. 1 (January 2016): pg. 91-103. DOI. This article is (C) Ophthalmic Communications Society, Inc. and permission has been granted for this version to appear in e-Publications@Marquette. Ophthalmic Communications Society, Inc. does not grant permission for this article to be further copied/distributed or hosted elsewhere without the express permission from Ophthalmic Communications Society, Inc. 